\title{
A psicopedagogia e o ensino musical
}

\author{
Alexsander Vanzela, Leida Calegário de Oliveira, \\ Marivaldo Aparecido de Carvalho
}

\begin{abstract}
Resumo: A música, como a educação escolar nos remete a esforços para a obtenção do saber. As técnicas musicais são conquistadas através de esforços diários e muitas vezes repetitivos, levando ao estudante a angústia de conseguir seus objetivos. Os sons, a música e as funções harmônicas estão presente do contexto de aprendizagem musical, exercendo sensações que são repassadas no momento em que o músico executa determinada sequência de acordes ou sequência de notas, gerando uma melodia. As angústias e ansiedades causadas pelos estudos podem ser aliviadas com um profissional da saúde e a psicopedagogia vem ao encontro do ensino musical auxiliando o aprendiz, oferecendo uma opção de intervenção para o auxílio no aprendizado de um instrumento musical.
\end{abstract}

Abstract: Music, like school education leads us to efforts to obtain knowledge. Musical techniques are won through daily efforts and often repetitive, leading to student anxiety to achieve your goals. Sounds, music and harmonic functions are present in the context of musical learning, exercising sensations that are passed when the musician performs some chord sequence or sequence of notes, creating a melody. The anxieties and anxieties caused by the studies can be alleviated with a health professional and psychopedagogy meets the musical teaching assisting the apprentice, offering an option of intervention for the aid in the learning of a musical instrument.

\section{Psicopedagogia e a música}

O processo educativo permeia aspectos necessários para o desenvolvimento e crescimento humano. A psicopedagogia está relacionada à aprendizagem, incluindo a musical, "auxiliando na identificação das dificuldades de aprendizagem e oferecendo opções de intervenção" (MELLO, 2011 ). Segundo Barbosa: 
A Psicopedagogia, enquanto conhecimento, interessa a todo aquele que se dedica à Educação, na medida em que possibilita uma análise das teorias relacionadas com as ações de aprender e ensinar, não apenas no sentido da prática didático-pedagógica, mas no substrato epistemológico que delas se origina para a formação do sujeito "aprendente". (BARBOSA, 2010)

"Educar-se em música é crescer plenamente e com alegria. Desenvolver sem dar alegria não é suficiente. Dar alegria sem desenvolver tampouco é educar" (GAINZA, 1988, p. 95). A música nos remete a sentimentos relacionados ao momento em que vivemos, por isso, usufruir da música pode ser prazeroso. Por outro lado, o aprendizado musical requer afinco, concentração, esforço pessoal e pode ser muito custoso e angustiante. Como é expresso esse lado angustiante da música? No excesso de horas dedicadas a exercícios repetitivos de apuração da técnica o estudante é desafiado em seu equilíbrio emocional, na manutenção da disciplina do ritmo de estudo e precisa se manter concentrado para superar objetivos. O filme "Whiplash, em busca da perfeição" apresenta um exemplo de como os músicos abrem mão dos aspectos pessoais da sua vida para alcançar reconhecimento artístico. Este filme retrata as angústias de um jovem baterista que busca desesperadamente atingir o elevado padrão exigido pelo maestro como prerrogativa para manter-se em um conjunto de jazz:

O filme levanta uma discussão interessante neste mundo do século XXI. Vale a pena submeter alunos a uma condição deqradante se for para criar um talento musical, um Charlie Parker? A fala de Fletcher em que afirma que a pior expressão que existe é "bom trabalho" é bem interessante. (CHAZELLE, D. 2014 apud SALGADO, L. 2015).

Outros filmes fazem relatos reais da vida de grandes músicos, como "Ray" de 2004, que conta como o envolvimento no meio musical provocou progressivos danos à convivência familiar, à saúde emocional e física de Ray Charles, um dos maiores tecladistas de blues e soul music. 
A aplicação de métodos psicopedagógicos desde os anos iniciais de estudo, visando a compreensão das fontes de ansiedade, das pressões internas e sociais a que o músico está submetido precisa ser enfatizada na educação musical. Além das bases técnicas, que requerem desenvolvimento de habilidades cognitivas e exercícios motoros, é preciso conciliar o lado criativo e, entendendo as linhas melódicas, trilhar seu próprio caminho como músico. Crescer e desenvolver a música, ter consciência na execução do instrumento, apurando a técnica, leitura e escrita musical. Para formar indivíduos musicalmente aptos a expressar-se através da música e a executa-la como arte, é preciso considerar o lado humano e pessoal dos estudantes, é necessário contemplar sua formação integral e respeitar sua identidade. A identidade de um músico pode ser reconhecida pelas características que imprime em suas composições e performance. Grandes guitarristas podem executar o mesmo solo e, sem alteração da melodia, podem ser reconhecidos pelos seus fãs. Existe uma transmissão de cumplicidade na execução do som, que o músico imprime ao tocar e que ao mesmo tempo é de difícil definição. Vai além do estilo de música adotado. Alguns guitarristas imprimem certa agressividade passional na execução, enquanto outros, ao tocar o mesmo solo, fixam uma ideia de organização metódica: o peso diferenciado em cada nota contribui para essa identidade e, além de transmitir sensações ao ouvinte, caracteriza o músico e sua música. A psicopedagogia pode auxiliar o professor em suas metodologias para que este possa, juntamente com o estudante, construir um processo de criação de identidade musical criativa, evitando processos de ansiedade extrema e depressivos prejudiciais à saúde emocional e física que decorrem dos estudos intensivos e também das sensações produzidas pelos sons.

A música contém uma "função harmônica que representa a sensação (emoção) que determinado acorde transmite para o ouvinte" ${ }^{\text {, }}$

1 http://www.descomplicandoamusica.com/harmonia-funcional/ acesso em 07/07/16. 
as funções harmônicas são divididas em função tônica, função dominante e função subdominante. Essas três funções transmitem sensações. A sensação de repouso, estabilidade e finalização está na função tônica, que é a que normalmente inicia a música. A sensação de tensão, que prepara para a tônica é a função dominante e por fim temos a função subdominante que fica entre a tônica e a dominante, é um meio termo tendo uma sensação de preparação, mas com uma menor intensidade e intensificando a tensão passa para a tônica. Na música a tônica está nos graus I, III e Vl; a dominante está nos graus V e VII e a subdominante nos graus IV e II, assim temos os sete graus do campo harmônico, que são feitas as harmonias musicais, ou seja, onde os acordes são encaixados para que haja um encadeamento natural das notas musicais. Tanto o músico quanto o espectador são expostos aos efeitos do som que durante um concerto se propaga e chega até os ouvidos dos espectadores. Os efeitos da sonoridade afetam o público, mas principalmente o músico, que deve se dedicar a ouvir e executar repetidas vezes uma mesma melodia no decorrer dos seus estudos ou atividade profissional.

O som é uma onda que vibra e se propaga, é uma forma de energia e, como tal, incute seu efeito em quem o escuta. "A música e o som, enquanto energia, estimulam o movimento interno e externo". (GAINZA, 1988). A experiência musical é iniciada no ventre materno quando o bebê escuta os batimentos cardíacos da mãe, os ruídos intestinais, sons externos e todos esses conjuntos de sons soam fortemente ao feto juntamente ao fluxo de sangue dos grandes vasos que abastecem o útero e a placenta. (NUNES, 2010).

A percepção da direção dos sons é um fenômeno que ocorre de maneira inconsciente e está presente desde cedo no ciclo de vida humano, sendo uma função relacionada com a sobrevivência: por volta de seis meses de idade um bebê normal já é capaz de localizar sons à sua volta (OLIVEIRA et al. 2008). 
Sabemos que os sons fazem parte do cotidiano, assim como a escrita e leitura fazem parte da sociedade para um objetivo comum, onde as pessoas leem e escrevem de forma espontânea e criativa e fazem o uso da comunicação. "A linguagem musical tem sido apontada como uma das áreas de conhecimentos mais importantes a serem trabalhadas na Educação Infantil, ao lado da linguagem oral e escrita" (NOGUEIRA, 2003), praticamente tudo em nossa volta emite um som e a música é a "combinação dos sons" (GALDINO, 2015).

A música estimula também o desenvolvimento psicológico da criança, pois contribui significativamente para que as crianças possam reestruturar suas emoções, alcançando um equilíbrio natural. Facilita também a liberação das fantasias, da imaginação, a criatividade, e através destas a criança pode se tornar um ser mais feliz. (LIMA e SANT'ANNA, 2014, p. 103)

Quando pensamos em música, "a sua ação implica num movimento" (GAINZA, 1988). Este movimento pode ser feito pelo indivíduo, através do canto ou da fala, ou pelo instrumento. O indivíduo que produz a música, que se expressa mediante os sons, segundo Gainza, demonstra maior ou menor capacidade segundo seu arquivo sonoro internalizado. "Assim, através da música que produz ou reproduz, o sujeito manifesta especialmente sua sensibilidade, o seu "sentido" rítmico, ou o seu "sentido" harmônico, melódico, tímbrico, etc." (GAINZA, 1988, p. 29). Em seu interior, o indivíduo está frequentemente processando informações, materiais sonoros e musicais, absorvendo e expressando em formas sonoras, corporais e verbais seus sentimentos, estimulando a imaginação.

A imaginação de uma música, mesmo nas pessoas relativamente não musicais, tende a ser notavelmente fiel não só ao tom e ao sentimento do oriqinal, mas também 'a altura e ao ritmo. A base disso é a extraordinária tenacidade da memória musical, qraças a qual boa parte do que ouvimos nos primeiros anos de vida pode 
ficar "qravado" no cérebro pelo resto de nossa existência. (SACKS, 2007, p. 12)

Esses processos internos determinam um vínculo criado para diferentes pessoas por meio da música.

O processamento dos materiais sonoros e musicais se dá no interior do sujeito, de tal forma que a energia proveniente da música absorvida metaboliza-se em expressão corporal, sonora e verbal, enqendrando diferentes sentimentos, estimulando a imaqinação e a fantasia, promovendo enfim, uma intensa atividade mental. GAINZA, 1988, p. 30)

Segundo Gainza, um indivíduo que executa um instrumento de forma imperfeita porque erra ou porque não fraseia adequadamente, não comunica sua afetividade ou não manifesta um grau aceitável de compreensão mental da obra, demonstrando suas deficiências. "Considerando as aprendizagens como o principal fator de desenvolvimento humano, Vigótski fazia uma distinção entre aprendizagens e conhecimentos espontâneos/cotidianos e os formais" (BENEDETT; KERR, 2009, p. 84).

Gainza faz um paralelo entre pedagogia e psicoterapia por tratar de certos problemas de comportamento musical. Pesquisando as causas das disfunções musicais fora da música, encontrou bloqueios que afetavam a capacidade de aprender devido a conflitos de personalidade. A insegurança pessoal de cada indivíduo fazia com que os mesmos desafinassem durante uma execução com o instrumento. Existia ali um "bloqueio afetivo que impedia de se expressarem quando tocavam o instrumento" (GAINZA, 1988, p.49).

"Um professor se dedica principalmente àqueles que tem problemas" (GAINZA, 1988, p. 54). Situações adversas levam o aluno ao não aprendizado musical, com causas que incluem problemas pessoais, concentração, a falta de instrumento e o pouco interesse nos estudos. Essas causas que afetam o indivíduo afetam também o aprendizado, pois 
sem o sujeito que aprende o aprendizado não é possível: "a aprendizagem é a apropriação, a reconstrução do conhecimento do outro, a partir do saber pessoal" (FERNÁNDEZ, 1994 apud MENDES, 2007).

O profissional da saúde poderá resolver situações como insegurança, ansiedade, instabilidade, dependência, dificuldade em focar o objeto musical e a incapacidade de perceber-se em relação à música. Mesmo quando os "sintomas" indicam casos leves, como explica Gainza (1988), é importante o encaminhamento desses indivíduos para profissionais que utilizam a psicoterapia ativa, sem interromper o trabalho musical, corrigindo a desordem produzida pela confusão objeto-sujeito musical.

É entendido que problemas com sentimentos pode ser um causador da deficiência no aprendizado musical. O uso de um software pode funcionar como ferramenta de apoio técnico, mas poderia também como suporte emocional, à medida que o aluno dispõe de algo concreto, material que o relembra das instruções do professor?

A United Nations Educational, Scientific and Cultural Organization (UNESCO) $^{2}$ traz em seu sítio informações sobre Tecnologias de Informação e Comunicação (TIC) que exercem um "papel cada vez mais importante na forma de nos comunicarmos, aprendermos e vivermos", a essas informações incidem em inclusões da tecnologia aos alunos, dentre outras, sendo a tecnologia uma ferramenta motivacional e facilitador para o aprendizado musical inclusive. Psicopedagogia e tecnologia da informação podem ser utilizadas conjuntamente para o aprendizado musical e ao mesmo tempo para manter a saúde emocional dos estudantes de música? O método proposto pretende contribuir para a resposta.

2Organização das Nações Unidas para a Educação, a Ciência e a Cultura. http://www.unesco.org/new/pt/brasilia/communication-and-

information/access-to-knowledge/ict-in-education/. Acesso em: 15/08/2016. 


\section{Ansiedade e a performance musical}

A performance musical é uma característica muito importante para o músico em suas apresentações em público. É frequente no Conservatório Estadual de Música "Lobo de Mesquita" (CEMLM) em Diamantina, Minas Gerias, alunos com dificuldades de execução resultante do alto nível de ansiedade, podendo acontecer que sua atuação diante de uma situação avaliativa ou de uma apresentação, represente naquele momento uma falta de atenção ou coordenação motora deficitária.

"O estudo da performance musical como um evento, um processo e o resultado das práticas performáticas devem se concentrar no comportamento musical e extramusical dos participantes e na interação entre participantes e plateia." (MIRANDA, 2013, p. 20).

A ansiedade é uma forma de proteção do ser humano que sinaliza uma situação de perigo, muitas vezes intensa e inapropriada às situações podendo ser maléfico e prejudicial. A sensação de frio na barriga, que pode ser comum nas pessoas em situações quando expostas ao público e que no caso dos músicos, se exponham com maior frequência, se sentindo coagidos por ser observados pela plateia ou apenas por seu professor em avaliações de instrumentos.

O fato dos alunos do CEMLM, iniciarem suas apresentações desde o início, no ciclo inicial ou de iniciação musical, faz com que estes alunos possam se acostumar e utilizar essa ansiedade antes das apresentações como "parte" da apresentação, em que ao passar do tempo este "costume" se torne uma sensação mais amena e quase imperceptível, trazendo a naturalidade necessária e tranquilizando a sua performance.

Rocha; Neto; Gattaz (2011) validando a tabela K-MPAl, constatou que existe um universo superior a 20 mil pessoas diretamente envolvidas com a performance musical, portanto afirmou em dados 
epidemiológicos que pelo menos 3 mil apresentam potencialmente casos de ansiedade, mais especificadamente fobia social.

A fobia social faz parte do conjunto dos transtornos de ansiedade, onde também estão inclusos a síndrome do pânico, a fobia específica, o estresse pós-traumático, o transtorno obsessivocompulsivo e o distúrbio de ansiedade generalizada. Esses transtornos são problemas emocionais comuns na população mundial e há a estimativa de que cerca de $15 \%$ a $35 \%$ sofram de algum desses transtornos (KOLB; WHISHAW, 2002 apud MIRANDA, 2013)

Verificamos que a ansiedade, bem como os sintomas como fobia social possuem fatores que estão predominantemente diários às situações humanas. Miranda (2013) relata que "as pessoas quando expostas em situações públicas, é comum a temer antecipadamente" (MIRANDA, 2013, p. 25). O fato dos músicos serem mais expostos a situações adversas, possibilita sensações inesperadas, podendo apresentar fatores para um controle emocional.

O sucesso na performance musical requer um excepcional controle motor fino, além de um profundo conhecimento da estrutura musical e da tradição da performance. Com toda essa complexidade envolvida na atividade musical, acrescida da pressão diante da plateia, não é de se surpreender que o quadro de ansiedade seja relativamente comum entre os musicistas. (ROCHA; NETO; GATTAZ, 2011, p.218)

Rocha; Neto; Gattaz (2011) relata que em crianças a ansiedade na performance não é um fator negativo, pois elas adoram plateias, ao contrário dos adultos que têm a sensação de parecer "...ridículo, dizer tolices, ser observado por outras pessoas, interagir com estranhos ou pessoas do sexo oposto e ser o centro das atenções. Mulheres são duas ou três vezes mais afetadas do que os homens, e essa relação parece ser a mesma na performance musical." (ROCHA; NETO; GATTAZ, 2011, p. 218). 
Finalizamos relatando que "a música não pode permanecer no silêncio solitário de quatro paredes, o palco é o seu lugar, local este há milênios, destinado à contemplação do público." (MIRANDA, 2013, p. 110). Situações de ansiedade podem ser controladas para uma melhora na performance musical, contribuindo para uma apresentação de qualidade e uma eficiência motora plausível.

\section{Conclusão}

O ensino musical requer perseverança. O indivíduo que decide ser um músico passa por situações de ansiedade, angústia, nervosismo, fadiga e muitas outras sensações que deriva da busca pela perfeição musical.

Muitas vezes o aprendiz não percebe o momento de angústia em que está vivendo devido a situações adversas em seu cotidiano. Seu professor de música observando o aluno e verificando que o mesmo precisa de ajuda, poderá indicar um profissional da saúde que utilizando da psicoterapia ativa, sem interromper o trabalho musical, corrigindo a desordem produzida pela confusão objeto-sujeito musical. A psicopedagogia, poderá auxiliar o aluno em suas conquistas, aliviando-o das sensações estressantes que o aflige, obtendo uma performance musical de acordo com seus objetivos.

Assim concluímos que a psicopedagogia e a psicoterapia são excelentes aliados do processo de aprendizagem musical.

\section{Referências Bibliográficas}

BARBOSA, Maria L. S.: Psicopedagogia e Música: Revisão Bibliográfica. I Simpósio Brasileiro de Pós-Graduandos em Música XV Colóquio do Programa de Pós-Graduação em Música da UNIRIO Rio de Janeiro, 8 a 10 de novembro de 2010. 
BENEDETT, Kática S.; KERR, Dorotea M.; A psicopedagogia de Vigótski e a educação musical: uma aproximação. Marcelina: Revista do Mestrado em Artes Visuais da Faculdade Santa Marcelina. São Paulo: Fasm, n.3, p.8097, 2009. Eu-você etc.

CHAZELLE, Damien: Filme Whiplash - Em busca da perfeição. EUA. Estreiou no Brasil em 08/01/2015, no Festival de Sundance em 2014. http://www.adorocinema.com/filmes/filme-225953/criticasadorocinema/ - acesso em 07/07/16.

FERNÁNDEZ, Alicia: Os Idiomas do Aprendente. Artimed 2001, ISBN: $9788573078213,2001$.

GAINZA, Violeta H. de: Estudos de Psicopedagogia Musical. Summus Editorial Ltda, vol. 31. São Paulo, 1988.

GALDINO, Viviane T. A música como ferramenta pedagógica no processo de aprendizagem. Revista Eventos Pedagógicos. Articulação universidade e escola nas ações do ensino de matemática e ciências. v. 6, n.2. (15 ed.) número regular, p. 258-267, jun/jul 2015.

KOLB, Brian; WHISHAW, Ian Q. Neurociência do comportamento. ISBN: 8520413927, 9788520413920Ed. Manole, 2002.

LIMA, Grasielle P. de; SANT'ANNA, Vera L. L.: A música na educação infantil e suas contribuições. Revista Pedagogia em Ação. ISSN 21757003. v.6, n.1, 2014.

MELLO, Maria I. de S. A. A música como instrumento de intervenção psicopedagógica. Venletrarte, Anais. Campos dos Goytacazes - RJ. Outubro de 2011 
MENDES, Rosali O.: A PSICOPEDAGOGIA ENQUANTO CIÊNCIA E A APRENDIZAGEM “CONHECENDO MELHOR”. 2007. 15/03/2007 - Fonte: http://www.psicopedagogia.com.br/artigos/artigo.asp?entrlD $=925$

MIRANDA, Jonathan G. e: Música no palco: ansiedade de performance musical em estudantes de música em Belém do Pará. Dissertação apresentada ao Programa de Pós Graduação em Artes do Instituto de Ciências da Arte da Universidade Federal do Pará, Belém 2013.

NOGUEIRA, Monique A. A música e o desenvolvimento da criança. Revista UFG, vol. 5, n.2, dez. 2003.

NUNES, Patrícia A. O.: Experiência auditiva no meio intra-uterino. Psicologia.com.pt - O portal dos psicólogos. 2009 - documento produzido em 09/01/2010.

OLIVEIRA, Aline C. de; ROCHA, Luciana P; LIMA, Vivian P; NETTO, Leônidas M; MENEZES, Pedro de L; COLAFÊMINA, José F.: Localização de fontes sonoras: a importância das diferenças dos limiares auditivos interaurais. Rev. soc. bras. fonoaudiologia. vol.13 no.1 ISSN 1982-0232. São Paulo Jan./Mar. 2008

ROCHA, S.F.; NETO, E.D.; GATTAZ, W.F.: Ansiedade na performance musical: tradução, adaptação e validação do Kenny Music Performance Anxiety Inventory (K-MPAI) para a língua portuguesa. 27/10/11.

Disponível em http:/ / www.scielo.br/scielo.php?script=sci_arttext\&pid=S0101 60832011000600001

SALGADO, Lucas. Crítico de cinema pela web. http://www.adorocinema.com/usuarios/B20120125122939960644419/ acesso em 08/08/2017.

SACKS, Oliver. Alucinações musicais, Companhia das Letras. SP. 2007 